\title{
Strategies for Success: Bringing Out the Best in a Learner
}

Marian Tyacke

Faced with the inadequacies of models of language teaching, researchers and practitioners have moved to models of language learning. Within this framework, many of us have attempted to characterize student learning styles and strategies. It is assumed that raising awareness of such styles and strategies will facilitate language development, by providing a basis on which a principled choice of activities can be made, and encouraging leamers to take on more "ownership" of the process.

This article argues that, even though we

\begin{abstract}
may not be able to change an individual's basic cognitive style, we may be able to make the learning process more transparent. It also suggests that strategy training can be useful, providing principles for such training, and practical suggestions for teacher training courses and classroom practice. Finally it proposes that syllabus design should take individual differences into account, and that such differences have to be carefully diagnosed and analyzed by the classroom teacher in collaboration with the learner.
\end{abstract}

As teachers, we are constantly searching for better ways to help our students learn. However, in spite of carefully chosen techniques and welldesigned materials, not all students make progress. Of course, some students are brighter than others, and some work harder than others, but this does not always account for the disparity of development, especially as there is evidence that certain very intelligent people have had great difficulty in learning a foreign language, however hard they work.

There are obviously other factors which contribute to success or failure, both affective and cognitive; however, I will argue that a crucial factor is the interaction between learning style (i.e. the specific way a learner deals with new information as a consequence of both the learner's personality and cognitive attributes) and learning context, and that any approach or methodology which fails to take this into account could constrain or discourage certain learners. Accordingly, a programme should include a clear identification of students' learning styles, observation of their reactions to the learning context and either

a) the provision of a "user-friendly" environment which matches their style, or at least is flexible enough not to constrain it, or

b) the provision of compensatory or coping strategies for dealing with a mismatched or constraining learning context. 


\section{Factors Which Affect Language Learning}

Second language acquisition research has tended to focus on a single variable at a time rather than a combination, a fact which makes it difficult to determine how factors interact with each other, much less how they interact with a complex learning context.

Motivation has been demonstrated to be an important ingredient for success (Gardner \& Lambert 1972), particularly a strong desire to identify with the target culture; however, paradoxically, too strong a desire might provoke high anxiety which increases chance of failure. It has also been suggested that good language learners are risk-takers (Beebe 1983), willing to enter the uncharted and uncertain realm of a second language and a second identity, or that they possess superior inferencing skills (Bialystok 1983) which obviously indicates that they are able to work beyond the surface level of the text. Other researchers have demonstrated relationships between field independence or tolerance of ambiguity and success in the language classroom (see Abraham 1985, Chapelle \& Roberts 1986, Naiman et al 1978). Field independence is defined as "the extent to which a person perceives part of a field as discrete from the surrounding field as a whole, rather than embedded, or ... the extent to which a person perceives analytically" (Witkin et al, 1977). Tolerance of ambiguity indicates a capacity to deal with unfamiliar territory, with complexity, with the unstructured and even with apparently contradictory situations. Such differences may account for the fact that some students may readily respond to a communicative approach, while others are horrified by what appears to be a lack of structure or linguistic rigor. In other words, people who have a low tolerance of ambiguity (AT) may be very happy in a quiet, structured environment, while those with a high tolerance may thrive in the multi-stimulus communicative classroom. As Chapelle and Roberts (1986:31) point out: "Although ambiguity is present in any L2 situation there is less in a formal language class in which individual elements of language are isolated for study than in an immersion situation in which the learner has to attend to all language cues simultaneously. A learner with little AT would be at a greater disadvantage in a situation with greater ambiguity." Furthermore, people whose style is analytical and serialistic may want to move through a course sequentially, gaining comprehension of each piece before they venture to an understanding of the whole, while others whose style is more holistic and synthetic may prefer to be surrounded by comprehensible input which they will sort out in their own personal way probably at a less conscious level. These cognitive biases which cause students to behave in a certain way in a learning situation cannot be ignored if we want to provide them with the most appropriate environment to foster their development. However, we are dealing with 
an extremely complex process which is not yet fully understood. Although we have 'focussed on the learner' at least since the seventies, what happens inside a student's head is still a mystery, in spite of valiant efforts to characterize the habits of good language learners, or isolated aspects of good language learning.

\section{Developing Good Language Learners}

In recent years, research has been undertaken that suggests that some good language learning habits can be taught, and consciously practised by individual students. (O'Malley et al 1984, Rubin \& Thompson 1982, Wenden 1983). At the same time, there is so far little evidence that any significant changes can be effected in an individual's learning style once he/she becomes an adult, and that any changes that take place are at a very superficial level, and perhaps not worth the investment of time and money. In other words, we might be able to teach a student better study skills (such as note-taking, or keeping contextualized vocabulary lists) or better learning management (such as setting realistic goals, and carrying out plans) without having any permanent effect on the way an individual processes information or approaches a task. This is not to downgrade the efforts that are being made, as these may help many students, if only temporarily, to successfully complete part of a programme and move on the next stage. Also, they may genuinely help students who are poor learners gain more control over their learning, or younger students who are beginning to develop metacognitive strategies especially in the area of organization. If strategy training can make learners more aware of their own strengths and weaknesses, and lead to possible modification, then it could be an important addition to a language learning programme, but it should not be done without reference to the learning style of the individual learner, as some strategies that work for one type seem to cause difficulties for others (Huang \& Van Naerssen 1988). However, there are strong suggestions in the literature that the most successful learners are those who are capable of adapting the learning approach to the task, i.e. if a careful and sequential analysis is called for, they analyze; if holistic apprehension is expected, they successfully switch. As Brown (1980:93) says:

"It has been suggested that the ideal language learner would be the one who was cognitively "flexible" so that he/she could take advantage of both his/her (Field Independent and Field Dependent) styles, and thereby benefit from the use of both L2 learning and acquisition situations."

Other researchers (Pask \& Scott 1972, Ramsden 1984, and Svenssen 1984) also stress versatility when describing successful learners, but prefer 
to differentiate between "serialistic" and "holists", claiming, after investigating learner behaviour in controlled experiments, that serialists concentrate on details and use logical analysis to learn, whereas holists tend to recapitulate as a whole, using illustrations, anecdotes, analogies and intuitions to build up the picture. The suggestion is that successful learners are flexible enough to move in both directions:

"A student who is versatile is not prone to vacuous globetrotting; he does indeed built up descriptions of what may be known by a rich use of analogical reasoning, but subjects the hypotheses to test and operationally verifies the validity of an analogy and the limits of its applicability." (reported in Entwistle 1981:94).

It is clear that both types of learning are necessary in successful language development; however, extremes in both directions may be doomed to failure. The extreme holist indulges in "globetrotting" (in Entwistle 1981:92-93) making "inappropriate or vacuous analogies" or generalizing from insufficient evidence and making hasty judgements. These learners may take too broad a perspective, making use of personal and idiosyncratic analogies which do not make sense to others. They may jump to conclusions without being able to explain to others the logical processes which have led to such conclusions and may work out supportive evidence later. Extreme serialist learners, on the other hand, may miss the significance of important analogies and may not be able to create a schema to consider how various elements interrelate or fit into a larger framework, even though they are much more conscious of each element. In these particular cases, remedial action may be warranted in the form of awareness raising of problem areas, and compensatory strategy training.

It seems extremely important, then, to build into any learning situation the opportunity for individuals to utilize their preferred style to its greatest advantage; however, it is equally clear that students must also learn the dangers of its deficiencies and excesses. As it would be difficult to change the basic nature of our individual learners, even if we wanted to, we should be examining ways of modifying their conscious strategies so that greater gains can be made in terms of language development. We can safely encourage greater flexibility in the individual learner by offering a flexible enough programme so that choices exist. But we have to develop sophisticated instruments or procedures to help students make the right choices, otherwise they are likely to choose on the basis of familiarity, rather than their true nature. Should we wait, then, until we know more about neurological processing before we try to develop such instruments or to teach "learning to learn courses" such as the ones devised by Willing and the Australian Adult Migrant Education Service (1986), or should we use what knowledge we have, with a strong dash of common sense, and 
say yes, we can move in a direction which will improve the situation without actually solving every problem.

\section{Developing Awareness of Individual Learning Styles and Strategies}

The following plan is designed to increase student awareness of their own learning potential in terms of what works best for them as individuals. It involves teacher training, classroom techniques and materials adaptation and production.

I would like to propose three guiding principles:

1. Training should encourage "deep" not "surface" learning, that is, an intention on the part of the student to reach understanding as opposed to increasing knowledge or simply performing a task (Entwistle 1987). This implies a deeper level than immediate comprehension of information. In terms of language learning, it involves a complex process of interpretation, reconstitution and integration into a knowledge structure.

Traditional study skill courses have been shown to have little lasting effect though initially comfortable and acceptable to the learner, particularly in a first language situation. They are recognizable and seem to be immediately useful. "Learning to learn" approaches are less familiar, and often greeted with suspicion, even hostility, if no immediate pay-off is perceived but can lead to "deeper learning" if carried out successfully. For example, Martin and Ramsden (1987) carried out a study which contrasted these two approaches in the history departments of two different British universities. In the first, study skills (such as note-taking, essay organization etc.) were explicitly taught by an expert. Although the students were initially enthusiastic, attendance declined rapidly until the group was quite small. The second group participated in unstructured group discussions aimed at increasing their learning potential by tapping their own strategies and sharing intuitions. This approach was greeted less enthusiastically initially, but attendance remained fairly constant. In the latter case, essay marks improved over a control group who did not take part in the discussions, whereas there was no significant difference between the first group and a group which received no study skill instruction.

We must consider, however, that these students already had a high level of conceptual organization. Would "study skills" training influence the outcome for those who have not had the opportunity to gain sound learning management skills? The work of Yorio (1989) dealing with students who are by and large poor urban immigrants with little traditional educational background, and who may even have acquired their language on the streets, indicates that this is so. They receive 
special counselling on "language facilitation", and can take part in inter-session workshops, or follow self-study programmes in a language resource centre staffed by tutors in order to upgrade their skills and to improve their study habits. The success of the programme is reflected in an increase in scores on a reading and writing test which they all have to pass as a university requirement. A further benefit of such programmes is that they may also provide foreign students with a set of cultural expectations which they can successfully exploit. What Westerners consider to be an effective logical development within an essay framework, for example, may not be obvious to writers from other cultures. Also analytical and inferencing skills may not come easily to students who come from educational systems which stress rote-learning. For the non-native learner, such non-linguistic factors may be the most significant outcome of the training.

But the most important question remains. How do we train for "deep" learning to take place: learning which goes beyond study skills and learning management programmes? Martin and Ramsden's study seemed to indicate that a greater awareness and an analysis of individual learning styles led to greater success, but a systematic analysis might require psychological training which few ESL/EFL teachers possess.

2. The training programme should be based on the notion of learner diversity, that is, that different learner types are capable of success, rather than the idealized notion of "The Good Language Learner" (Naiman et al 1978, Rubin 1975, Stern 1975)

This, of course, depends on clear and careful diagnosis carried out collaboratively with each student at a level which he or she can understand. Because of the lack of psychological training mentioned above, we have tended to rely on instruments designed by educational psychologists to provide a profile of learning styles (for examples, see Gregorc 1982, Kolb 1971, Myers-Briggs 1987). However, such instruments depend on subjective reports, and may consequently be less accurate than more objective measures. Also, they tend to work best within a culture where there is a shared understanding of such terms as "conventional" and "conspicuous" (Myers-Briggs), terms which might have different meanings for people from other cultures.

Recognition of diversity also implies a "descriptive" rather than a "prescriptive" approach to strategy training, providing a set of options rather than a list of "the right strategies". The training should not intervene with the learning process, but rather make it transparent, so that the learner is empowered to make his or her own changes. However, it should encourage versatility without destroying effective but idiosyncratic study methods. 
3. The training programme should be integrated with, not separated from the skill or subject to be learned, linked to both context and content. For example, an academic learning English overseas and an unskilled immigrant in Toronto learning survival skills are two radically different contexts, requiring different kinds of strategy training.

As far as content is concerned, we know, for example, that developing reading skills involves a certain set of cognitive strategies such as predicting, hypothesizing, testing hypotheses against data, contextualizing, inferencing, selecting, discarding and storing. All of these can be demonstrated and overtly practised as an integral part of a reading class. In this way we can focus on the process, rather than on the comprehension of product, as well as providing ourselves with essential information for the diagnosis of what is successful for the individual reader.

Let us now consider ways of applying some of these principles in teacher training courses and learner training in the classroom.

\section{Teacher Training}

First, all good teachers already take learner variables into account whenever they step into the classroom. However, they may be doing it intuitively and unsystematically and this is where we can make improvements.

The following are perhaps the most important things we can add to teacher training programmes:

1. the development of self-awareness: that is, awareness of the teacher's own learning style, together with an analysis of how that has affected teaching style. For example, someone who enjoys rule-learning as a way of developing language skills will probably use such techniques in classroom practice. The Learning Style Questionnaires of Gregorc et al can play an important role here if handled appropriately as they are useful as starting points for discussion. In addition, teachers can analyze why they respond well to certain student types, and more negatively to others.

2. Teachers can also be trained to use classroom observation techniques which might involve data collection based on inventories of cognitive strategies (O'Malley et al 1985, Oxford et al 1987, Rubin 1981, Wenden 1985), interviews with learners, journals in which learners map their own development, (Tyacke and Mendelsohn 1986), or thinkaloud protocols where students attempt to describe out loud what is going on in their heads while carrying out a language activity. (Block 86 , Hosenfeld 77, Tyacke \& Mendelsohn 1988). They could also practise audiotape and videotape recording of interviews and group discus- 
sion. Most of these can be carried out as an integral part of the classroom process if planned carefully by teachers themselves.

3. Teachers can be trained to use classroom activities which are useful teaching tools, but which also provide diagnostic information regarding individual student performance. For example "The Communicative Checklist" devised by Mendelsohn et al 1983 encourages both students and teachers to analyze the discourse from the point of view of the speaker and the hearer.

4. Teachers can be trained to create, adapt and select materials which offer a variety of learning experiences. For example, a reading textbook which relies primarily on $\mathrm{T} / \mathrm{F}$ factual recall and inferencing exercises could be supplemented by activities involving summaries of main ideas, debate of key issues, or identification of grammatical links, thus appealing to different learner types. The materials development should include discussion of the different cognitive demands of each task. In other words, how does synthesizing information in order to establish a main idea differ from recognizing, say, an adverbial clause which signals a time relationship.

\section{Learner Training}

1. Adult learners should be provided with some control over the process. In reading classes, for example, longer reading activities followed by a student-driven discussion of "their" choice of main ideas, rather than a multiple choice list devised by the teacher, can be employed. In talking and listening classes, allowing students to stop an audiotape or videotape at points where they are trying to make sense of the message rather than the teacher always imposing a pattern of understanding by pre-determining student difficulties may lead to more successful learning. Provision of activity options, as well as evaluation and feedback options allows the learners to follow their own developmental paths.

2. Adult learners can be made more aware of their own learning style. The classroom observation techniques outlined in the teacher training section come into play here. A selection can be used to help learners perceive their strengths and weaknesses and teachers determine priorities and gaps. Think aloud protocols, for example, can make students aware of their less successful strategies when they are able to compare them with more successful colleagues. (However, some learners, usually the more analytical types, are better at articulating the process than others, as more holistic thinkers seem to find it difficult to reconstruct thought patterns.)

Interviews at strategic points of the course can provide useful information, especially with students who are making little progress. Also, 
journals which describe their planning process when working on a written assignment, or their strategies when listening to a news broadcast may bring to light reasons for unsuccessful language development. Questionnaires regarding preferred learning styles can be discussed in class, and may even be used to form like groups to carry out specific activities.

Ultimately, this awareness should help learners who subsequently have to cope with less flexible learning contexts recognize problems before they develop, and adopt strategies which may not be their preferred ones, but which are still within their comfort zone, in order to deal with a programme or a teaching style which does not match the learning style.

3. Adult learners can be trained to monitor their own progress. At appropriate intervals, for example, teachers can check learner perceptions by asking such questions as "What works for you?" "Why did you use/choose $\mathrm{X}$ rather than $\mathrm{Y}$ ?" "Did you find the activity interesting, useful, easy?" etc. Attitude scales based on the last question can also be added at the end of a written activity so that teachers can check later to find out how learners responded to particular tasks. If learners have access to self-directed learning modules, their preferences can be tracked and analyzed over time, which will add further information regarding their learning profile.

4. Adult learners can be trained to share successful strategies with their peers.

Successful students can "teach" less successful ones in very specific situations, making sure that everyone has the opportunity of demonstrating their own strengths at some point. Group discussions which are proactive rather than reactive, (that is, they are designed to plan strategies for dealing with an assignment rather than responding to a prompt) can also help in this regard. The teacher must work hard to provide a supportive environment so that students can explore a variety of ways of approaching a task, and be confident that the teacher is not going to require one particular way, and that other students will respect their individual way of doing things.

5. Adult learners can be trained to transfer successful strategies to new situations.

As Sawkins (1987:63) suggests:

The teacher should teach for transfer. The problem is the same for learning strategies as for thinking skills. Many learners do not carry over principles to other contexts. The same strategies must be practised in varied contexts to help the learner generalize. 
For example, demonstrating relationships wherever possible between form and function teaches basic principles which the student can then relate to other situations (See Allen 1977). A checklist can be devised to find out what reading or listening strategies the student utilizes in a first language situation and comparisons made with what the same student does in a second language situation. This can be done at the beginning and end of a course to estimate what development has taken place. (See Tyacke $\&$ Saunders 1979). The same checklist can be used to diagnose strategy use so that remedial action can take place. For example, an individual may be using "contextualizing" strategies successfully in both languages, and needs to be challenged with more complex texts. Another may be successful in the first language, but may have to practise with simpler texts in the second. For others, it may even be necessary to overtly teach "contextualizing" as a strategy. (See Tyacke \& Saunders 1979)

Much of what has been described here is already being carried out by teachers who believe that taking the learner into account is part of any good pedagogical approach. However, it is important that whatever we decide to do is based on a careful diagnosis of the differences (not only in needs, but in learning profiles) that exist in every class we teach, rather than on a pre-determined and inflexible methodology.

By adopting this approach, we provide opportunities for individual learners to operate within their own comfort zone. We also "bias for best" in the sense that individual learners are free to practise their preferred strategies, rather than wasting their energy attempting to adapt to a situation which requires ones which they find difficult. Finally, by raising awareness of their own learning styles, we empower them to cope more effectively with any future learning context.

\section{REFERENCES}

Abraham, R.G. (1985). Field Independence-Dependence and the Teaching of Grammar. Tesol Quarterly, 20 (4), 689-701.

Allen, P. (1977). Structural and Functional Models in Language teaching. TESL Talk, Vol 8, No 1, 5-15.

Beebe, L.M. (1983). Risk-taking and the Language Learner. In H.W. Seliger \& M.H. Long (Eds), Classroom Oriented Research in Second Language Acquisition, Rowley, Mass: Newbury House, 39-65.

Bialystok, E. (1983). Inferencing: Testing the "Hypothesis Testing" Hypothesis. In H.W. Seliger \& M.H. Long (Eds), Classroom Oriented Research in Second Language Acquisition, Rowley, Mass: Newbury House, 104-123.

Block, E. (1986). The Comprehension Strategies of Second Language Readers. Tesol Quarterly 20 (3), 463-494. 
Brown, H.D. (1980). Principles of Language Learning and Teaching. Englewood Cliffs, New Jersey: Prentice-Hall.

Chamot, A. Uhl \& J.M. O'Malley. (1985). Using Learning Strategies to Develop English as a Second Language. Focus 16, Rosslyn, Virginia: National Clearinghouse for Bilingual Education.

Chapelle, C. \& C. Roberts. (1986). Ambiguity, Tolerance and Field Independence as Predictors of Proficiency in English as a Second Language, Language Learning 36 (1), 27-45.

Entwistle, N. (1981). Styles of Learning and Teaching. Chichester: John Wiley \& Sons.

Entwistle, N. (1987). A model of the Teaching Learning Process Student Learning. Milton Keynes U.K. Open University Press 13-28.

Gardner, R.C. \& W.E. Lambert. (1972). Attitudes and Motivation in Second Language Learning, Rowley, Mass. Newbury House.

Gregorc, Anthony F. (1982). An Adult's Guide to Style. Maynard, Mass.: Gabriel Systems Inc.

Hosenfeld, C. (1977). A preliminary investigation of the reading strategies of successful and non-successful second language learners. System 5(2), 110-123.

Huang X.H \& M. Van Naerssen. (1988). Learning Strategies for Oral Communication. Applied Linguistics 6, 237-307.

Kolb, D., Rubin \& McIntyre. (1971). Organizational Psychology: An Experiential Approach. Englewood Cliffs, New Jersey: Prentice-Hall.

Martin, E. \& P. Ramsden. (1987). Learning Skills, or Skill in Learning? In J.T.E. Richardson, M.W. Eyesenck, \& D.W. Piper (Eds). Student Learning. Milton Keynes, U.K. Open University Press 155-168.

Mendelsohn, D., M. Tyacke, M. McNerney, V. McDonough. (1983). Checklist for Providing Communicative Feedback in a Talking Class SCS, University of Toronto.

Myers-Briggs Type Indicator. (1987). Consulting Psychologists Press, Palo Alto, California.

Naiman, N., M. Frohlich, H.H. Stern, \& A. Todesco. (1978). The Good Languagi Learner. Research in Education Series/7, Ontario Institute for Studies in Education.

O'Malley, J.M., A Uhl Chamot, G. Stwener-Manzanares, L. Kupper \& R.P. Russo. (1985). Learning Strategies Used by Beginning and Intermediate ESL students. Language Learning, 35(1), 21-46.

Oxford, R., M. Nyikos \& D. Crookall, (1987). Learning Strategies of University Foreign Language Students. Paper presented at the TESOL Convention, Miami, Florida. 
Pask, G. \& B.C.E. Scott. (1972). Learning Strategies and Individual Competence. International Journal of Man-Machine Studies 4: 217-253.

Ramsden, P. (1984). The context of learning. In F. Marton, D.J. Hounsell, \& N.J. Entwistle (Eds.). The experience of learning. 144-164. Edinburgh, Scottish Academic Press.

Rubin, J. (1975). What the good language learner can teach us. TESOL Quarterly 9 (1): 41-45.

Rubin, J. (1981). Study of the Cognitive Processes in Language Learning. Applied Linguistics 11(2), 118-131.

Rubin, J. \& I. Thompson. (1982). How to be a More Successful Language Learner. Boston, Mass; Heinle \& Heinle.

Sawkins, M. (1987). Training for Independence in Learning. TESL Canada Journal Vol 5(1).

Svensson, L. (1984). Skill in Learning. In F. Marton, D.J. Hounsell, \& N.J. Entwistle (Eds.) The experience of learning. Edinburgh. Scottish Academic Press.

Tyacke, M. \& J. Saunders. (1979). Functional Reading Using Found Materials. TESL Talk 10, 1\&2.

Tyacke, M. (1983). Levelling the Multi-Dimensional Syllabus. Paper presented at Symposium on Curriculum Design. TESL Ontario Conference, Toronto.

Tyacke, M. \& D. Mendelsohn. (1986). Student needs; cognitive as well as communicative. TESL Canada Journal, Special Issue 1, 171-183.

Tyacke, M. \& D. Mendelsohn. (1988). Classroom Implications of Learner Diversity. Language Teaching Strategies Vol 3 Faculty of Arts and Science, University of Toronto 35-43.

Wenden, A. (1983). Literature Review: The Process of Intervention. Language Learning, 33(1), 103-121.

Wenden, A. (1985). Learner Strategies. TESOL Newsletter xix(5), 1.

Willing, K. (1989). Helping Adults Develop their Learning Strategies. Adult Migrant Education Service, New South Wales.

Witkin, H.A., C.A. Moore, D.R. Goodenough, \& P.W. Cox. (1977). Field dependent and field independent styles and their educational implication. Review of Educational Research 47 1-64.

Yorio, C.A. (1989). The Other Side of the Looking Glass. Journal of Basic Writing. CUNY 8.1: 32-45.

\section{THE AUTHOR}

Marian Tyacke is Associate Director, Programme of the School of Continuing Studies, University of Toronto. She has taught ESL for many years and is presently conducting classroom research in learner strategies and the reading process. She is also responsible for the COPE, an English proficiency test for university admission. 